\title{
Changes of abdominal muscle activity according to trunk stabilization exercises using a Swiss ball
}

\author{
Suk Min Lee ${ }^{a}$, Hee Sung Lim ${ }^{\mathrm{b}(}$, Hyo Jin Byun ${ }^{\mathrm{a}(}$, Myung Joon Kim ${ }^{\mathrm{c}(}$ \\ ${ }^{a}$ Department of Physical Therapy, College of Health and Welfare, Sahmyook University, Seoul, Republic of Korea \\ ${ }^{b}$ Department of Physical Education, College of Sport Science, Korea National Sport University, Seoul, Republic of Korea \\ 'Department of Physical Therapy, Kyungdong University, Wonju, Republic of Korea
}

Objective: The purpose of this study was to compare the activities of the abdominal muscles according to trunk stabilization exercises using Swiss ball in normal individuals.

Design: Cross-sectional study.

Methods: Ten healthy university students participated in this study. The subjects were required to complete the following three exercise positions: Exercise position 1, sitting on a Swiss ball and lifting the legs; Exercise position 2, pushing to a plank position from an ending position; and Exercise position 3, push-up posture with the legs on a Swiss ball. Changes in the trunk muscle activities were estimated using Biometric electromyography (EMG). Activities of the dominant side internal oblique muscle (IOM) and external oblique muscle (EOM) were estimated in all participants. The maximal voluntary isometric contraction (MVIC \%) was measured to standardize the EMG signals for the IOM and EOM during maximum resistance when sitting up with each shoulder pointing towards the contralateral pelvis with knees bent and both arms crossed on the chest for 5 seconds.

Results: There was a significant difference in the activity of the internal and external oblique muscles between Exercises 1 and 2 and Exercises 1 and $3(p<0.05)$. Furthermore, the IOM/EOM activity ratio was the greatest during Exercise 3 and the smallest during Exercise 1. IOM and EOM activities were the greatest during Exercise 2 with greater EOM activity.

Conclusions: In future studies, it will be necessary to investigate muscle activities by supplementing the above-mentioned limitations during the stabilization exercise. The results of this study may be used as a basis for controlling the intensity and frequency of exercise while prescribing trunk stabilization exercises.

Key Words: Abdominal muscle, Electromyography, Exercise training

\section{Introduction}

Because of a high level of professionalization and automatization in the modern society, reduced physical activities and lack of exercise have inevitably led to a higher incidence of musculoskeletal diseases. In particular, various diseases and pain of the lumbar spine are key factors that undermine an individual's quality of life [1]. Because the human spine is naturally curved, an inappropriate posture that weakens the functions of muscles and ligaments that support the spinal area and excessive movement of the lower back may re- sult in low back pain [2].

Low back pain occurs due to poor trunk stability [3]. Trunk stability refers to the musculoskeletal ability to maintain balance when faced with a small disruption of motor control [4]. Trunk stabilization refers to the controlling of muscles needed to maintain stability around the trunk. Trunk stability is dependent on the harmonious activity of many trunk muscles, where muscles in the front, back, and sides of the spine produce a stable and potent contraction. Stability is acquired in the momentary postures and after putting various loads on the spine [5]. Trunk muscles are the source of all strength

Received: 25 July, 2019 Revised: 16 September, 2019 Accepted: 17 September, 2019

Corresponding author: Hee Sung Lim (ORCID https://orcid.org/0000-0002-6259-468X)

Department of Physical Education, College of Sport Science, Korea National Sport University, 1239 Yangjae-daero, Songpa-gu, Seoul 05541, Republic of Korea Tel: 82-10-6890-7162 Fax: 82-2-410-6927 E-mail: hslim2002@hotmail.com

(a) This is an Open-Access article distributed under the terms of the Creative Commons Attribution Non-Commercial License (http://creativecommons.org/licenses/ by-nc/4.0) which permits unrestricted non-commercial use, distribution, and reproduction in any medium, provided the original work is properly cited.

Copyright $(\odot 2020$ Korean Academy of Physical Therapy Rehabilitation Science 
and mobility of the human body, and they maintain balance every time we move the body and also appropriately maintain the musculoskeletal structure [6].

Muscles that contribute to trunk stabilization are those that are positioned deep within the body and help in increasing the stability, such as local muscles (transverse abdominal, internal oblique muscle [IOM], and multifidus muscle) and global muscles (rectus abdominis, and erector spinae muscle), which are located outside the body and generate force and torque [7].

Therefore, stability of the low back, which can be considered as the center of the body, helps increase the efficiency of various exercises and prevents low back injuries while serving as the basis of the body's functional activities [8]. Previous studies on trunk stability have focused on the actions of the individual muscles, such as transverse abdominal and multifidus, using various exercise equipment and methods. However, some recent studies on biomechanics and muscles argued that because the contribution of the muscles involved in spinal stability cannot be clearly distinguished between the local and global muscles, appropriate coordination of the local and global muscles is crucial for maintaining the spinal stability $[9,10]$. Therefore, the ratio of the local to global muscle activity can be considered more important than the activity of each muscle. Among these, the internal oblique abdominal muscle/rectus abdominis muscle and IOM/external oblique muscle (EOM) activity ratios are important to prove that there may be lower rectus abdominis muscle and EOM activities compared with activity ratios of other muscles to mobilize them efficiently [11].

Other previous studies have reported that it is important to prevent excessive loading and unnecessary spinal movement when moving the extremities by increasing the lumbar stability by strengthening the EOM, IOM, and transverse abdominal muscle, which act as a corset around the lumbar spine to effectively manage chronic low back pain [12-16]. Furthermore, it has been reported that trunk stabilization exercise generally activates the local and global muscles simultaneously, thereby protecting the spinal joint structure from repetitive micro injuries or recurrent pain and have been used to ameliorate low back pain and improve functional impairments [17].

Swiss ball exercise requires good balance in order to maintain the same posture on the soft ball, so it is possible to relax the tension or tighten the lumbar muscles with low back pain and improve the range of motion of the spinal joint and it can reduce the pressure on the disc to maintain spine alignment [18]. Therefore, Swiss ball exercises for trunk stabilization have been reported to strengthen muscle strength, endurance, flexibility, and coordination while comprehensively improving reflexes, perception, and sense of balance to enhance the balance ability [19]. In particular, trunk stabilization exercises coupled with Swiss ball more strongly stimulates proprioception, which improves the sense of balance and ability to maintain balance, ultimately improving physical function [20]. Depending on the distance between the body and the ball, and the position of the limb supporting the ball, the Swiss ball movement can be performed in various movements [21]. The rotational force produced by the trunk in an unstable support base depends on the position of the Swiss ball and posture on the Swiss ball, which may have a training effect through the activation of the external and internal abdominal muscles [15,22]. However, the lumbar spine is anatomically limited to the movement of rotation between the vertebrae by the facet joint because it may cause shear force between the vertebrae and risk of injury when proper muscle activation does not occur [15,23,24]. Since the Swiss ball exercise is friendly and easy to perform, even though it is possible to perform various movements $[25,26]$, training methods according to the fitness level and the quantitative basis for this situation are insufficient.

\section{Methods}

\section{Participants}

Ten healthy male and female college students were enrolled in this study. Individuals with an injury, those with orthopedic diseases, and those undergoing weight training that may affect the mechanical structure of the abdominal muscles were excluded. Prior to data collection, participants were given a thorough explanation about the purpose and method of this study, and informed consent was obtained. This study was reviewed and approved by the Institutional Review Board of Sahmyook University (IRB No. 2-7001793-AB-N-012019089HR). The sample size was calculated by G-Power ver. 3.1.9.2 (University of Dusseldorf, Dusseldorf, Germany). Table 1 shows physical characteristics of the enrolled participants.

\section{Procedure}

\section{Estimation of the muscle activity}

Participants underwent a pretest. They arrived at the laboratory 30 minutes before the start of the exercise and took ad- 
Table 1. The general characteristics of participant $\quad(\mathrm{N}=10)$

\begin{tabular}{ccc}
\hline Age $(\mathrm{y})$ & Height $(\mathrm{cm})$ & Weight $(\mathrm{kg})$ \\
\hline $22.0(1.4)$ & $169.2(3.9)$ & $59.7(4.7)$ \\
\hline
\end{tabular}

Values are presented as mean (SD).

Table 2. Sites for EMG electrode attachment

\begin{tabular}{cc}
\hline Muscle & Attachment site \\
\hline $\begin{array}{c}\text { Internal oblique } \\
\text { muscle }\end{array}$ & $\begin{array}{c}\text { Midpoint between the navel and superior } \\
\text { anterior iliac spine }\end{array}$ \\
$\begin{array}{c}\text { External oblique } \\
\text { muscle }\end{array}$ & $15 \mathrm{~cm}$ lateral from the navel \\
\hline
\end{tabular}

EMG: electromyography.

equate rest prior to beginning the experiment. Changes in the trunk muscle activities were estimated using Biometric electromyography (EMG). Activities of the dominant side IOM and EOM were estimated in all participants. Sites for EMG attachment are shown in Table 2.

To estimate the trunk muscle activity during varying trunk stabilization exercises, three trunk stabilization exercises were used, namely, lifting the legs while sitting on a Swiss ball, pushing to a plank position from an ending position, and push-up posture with the legs on a Swiss ball. The order of the three trunk stabilization exercises was chosen randomly. Prior to beginning the experiment, participants were given a thorough explanation of each exercise, and they began exercise after the 'start' cue.

To standardize the EMG signals during stabilization exercise, the maximal voluntary isometric contraction (MVIC \%) was measured. MVIC for the IOM and EOM were measured during maximum resistance when sitting up with each shoulder pointing towards the contralateral pelvis with knees bent and both arms crossed on the chest. MVIC was initiated with the 'start' cue. The participants were instructed to produce maximum isometric contraction and they were verbally encouraged to maintain it for 5 seconds. The highest mean MVIC value was used for the corresponding muscle. The participants rested for 30 seconds between the measurements of activities of each muscle. The MVIC values for each muscle were measured, and all muscle contraction measurements were recorded by one examiner under the same conditions. All exercises were considered to be completed only when the posture was maintained for at least 5 seconds. Three measurements were taken repeatedly, and the mean of these three measurements was computed. The

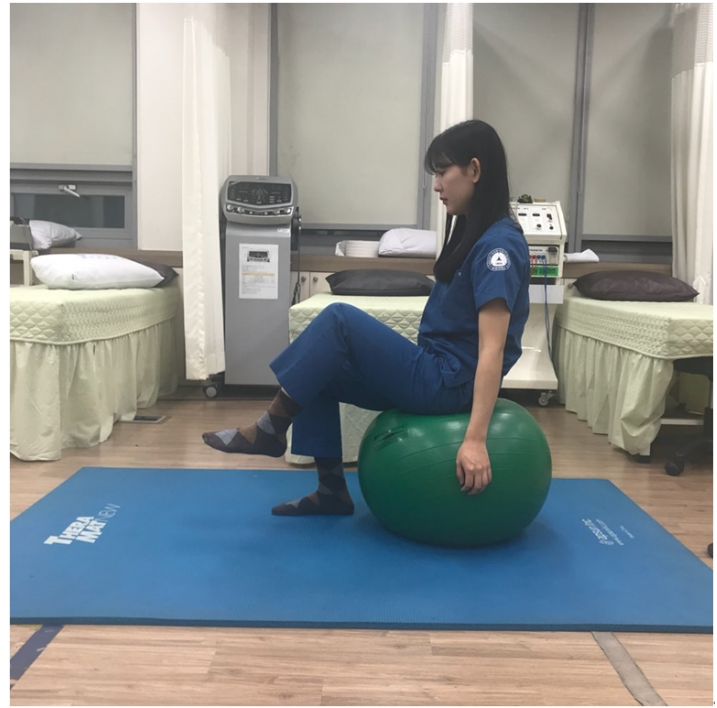

Figure 1. Exercise 1: lifting legs while sitting on a Swiss ball.

composition ratio of EMG activity for each muscle was computed by setting the sum of the \% MVIC for the left and right IOM and EOM as $100 \%$. The participants took a 30 seconds rest between exercises.

\section{Exercises}

(1) Exercise 1: lifting legs while sitting on a Swiss ball

With feet shoulder-width apart, participants sat on a Swiss ball, maintaining the natural spinal curvature with their eyes gazing forward and their trunk upright. They placed both their hands on the Swiss ball comfortably and in the seated position, lifted their legs at least $10 \mathrm{~cm}$ from the ground (Figure 1) [27].

\section{(2) Exercise 2: pushing to a flank position from an} ending position

With the knees bent at $90^{\circ}$ and back straight, the elbows were kept straight with the shoulder hunching approximately $30^{\circ}$. Both the hands were placed on the center of the Swiss ball. The examiner pushed the Swiss ball forward. While maintaining a neutral position of the spine and pelvis, participants placed their wrists on the Swiss ball. While pushing, the shoulder was bent at $90^{\circ}-100^{\circ}$ and the proximal side of the wrist was placed near the center of the Swiss ball. This posture was maintained for 5 seconds (Figure 2). 


\section{(3) Exercise 3: push-up position with the legs on the} Swiss ball

With the legs on the Swiss ball, participants spread their legs shoulder width apart (Figure 3) [27].

\section{Data analysis}

The data were processed using IBM SPSS Statistics for Windows, Version 21.0 (IBM Co., Armonk, NY, USA) as follows. The changes in trunk muscle activity across the three types of trunk stabilization exercises were analyzed using a one-way repeated measures ANOVA with the Duncan test as used as the post-hoc test. The statistical significance was set at $\alpha=0.05$.

\section{Results}

This study estimated the trunk muscle activity during various exercises in five men and five women in their 20 s. Table 3

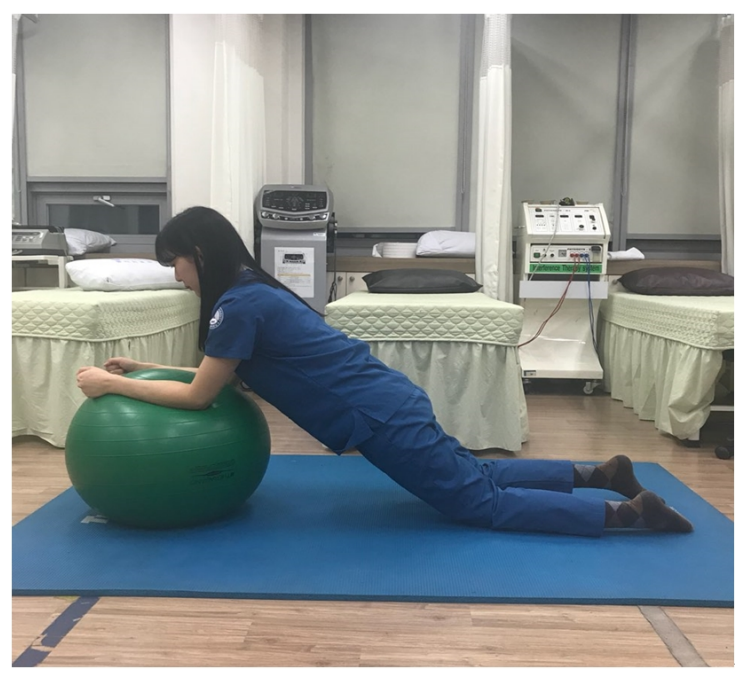

Figure 2. Exercise 2: pushing to a plank position from an ending position. shows the activities of each trunk muscle according to the exercise method. There were significant differences in IOM and EOM activities across the three types of exercise $(p<$ $0.05)$.

The IOM activity significantly differed between Exercises 1 and 2 and Exercises 1 and $3(p<0.05)$. However, it did not significantly differ between Exercises 2 and 3 (Table 3 ). As shown in Table 3, the EOM activity significantly differed between Exercises 1 and 2, Exercises 1 and 3, and Exercises 2 and $3(p<0.05)$.

Furthermore, the IOM/EOM activity ratio was the greatest during Exercise 3 and the smallest during Exercise 1. IOM and EOM activities were the greatest during Exercise 2 with greater EOM activity (Figure 4).

\section{Discussion}

This study aimed to investigate the effects of three types of trunk stabilization exercises using a Swiss ball on IOM and EOM activities in healthy men and women in their $20 \mathrm{~s}$.

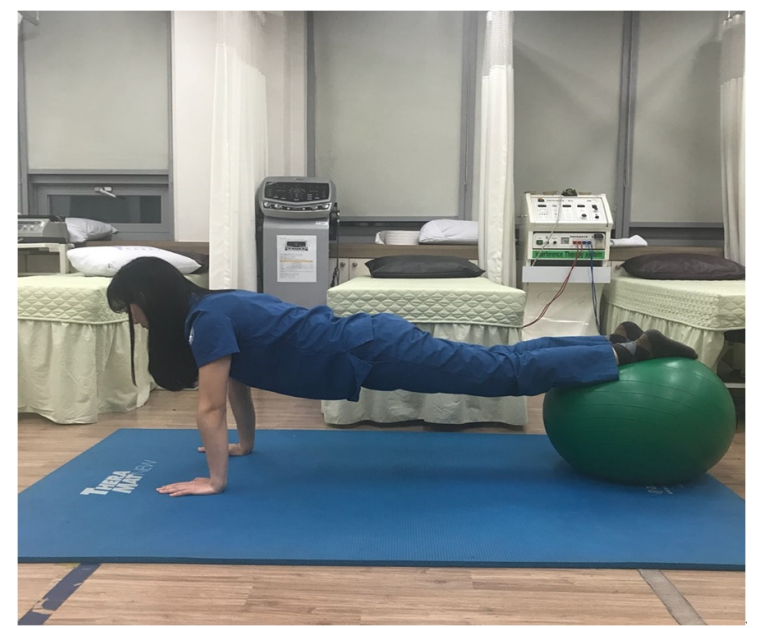

Figure 3. Exercise 3: push-up position with legs on a Swiss ball.

Table 3. The comparison of IOM and EOM activity during different exercises

$(\mathrm{N}=10)$

\begin{tabular}{lcccccccc}
\hline & \multicolumn{3}{c}{ Internal oblique } & & & \multicolumn{3}{c}{ External oblique } \\
\cline { 2 - 3 } & Exercise 1 & Exercise 2 & Exercise 3 & & Exercise 1 & Exercise 2 & Exercise 3 \\
\hline Mean (SD) & $21.309(2.894)$ & $47.100(3.966)$ & $46.480(5.817)$ & & $19.426(4.512)$ & $62.010(4.287)$ & $41.760(4.365)$ \\
$\mathrm{F}(p)$ & & $21.048(<0.001)$ & & & & $44.206(<0.001)$ & \\
\hline Post-hoc & Exercise 1-2 & Exercise 1-3 & Exercise 2-3 & & Exercise 1-2 & Exercise 1-3 & Exercise 2-3 \\
$p$-value & $<0.001$ & $<0.001$ & 0.917 & & $<0.001$ & $<0.001$ & 0.017 \\
\hline
\end{tabular}

IOM: internal oblique muscle, EOM: external oblique muscle, Exercise 1: lifting legs while sitting on a Swiss ball, Exercise 2: pushing to a plank position from an ending position, Exercise 3: push-up position with legs on a Swiss ball. 


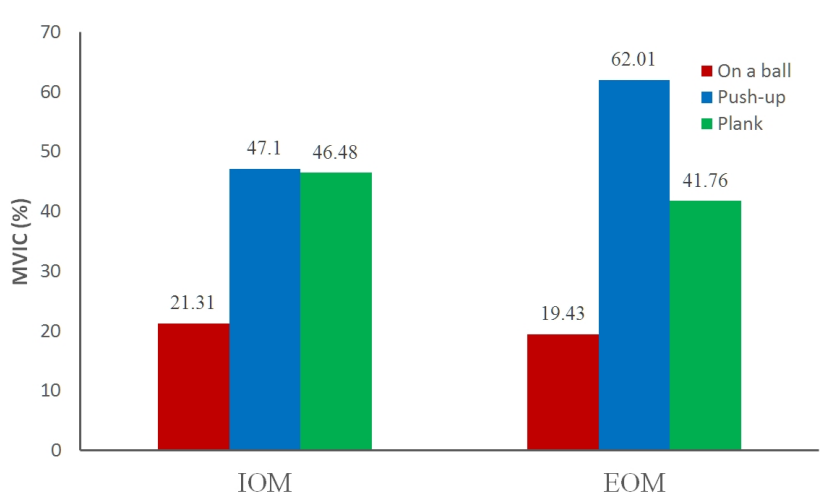

Figure 4. IOM/EOM muscle activity ratio according to the trunk stabilization exercise. IOM: internal oblique muscle, EOM: external oblique muscle

The purpose of trunk stabilization exercise is to improve motor control by altering the patterns of trunk muscles, thereby maintaining appropriate muscle coordination and generating adequate trunk stability against external resistance. Previous studies reported that the level and ratio of local and global muscle activity are important indices for muscle recruitment pattern and are helpful for understanding trunk muscle activity during various motions in daily living [28,29]. Richardson et al. [16] and Hall and Brody [22] assumed a state of high local muscle activity during stabilization exercise as an adequately stable state of the trunk. On the other hand, they argued that excessive global muscle activity generates spinal overload, and thus, induces pain, where the resulting compression increases the pressure of the intervertebral disc. Furthermore, because trunk stability is crucial in daily living, the authors proved that the transverse abdominal muscle is involved in trunk stability by measuring EMG in the trunk while raising an arm and revealing that the transverse abdominal muscle activity precedes upper and lower limb muscle activities. Along with the IOM and EOM, the transverse abdominal muscle contributes to spinal robustness by increasing the intraabdominal pressure and serves as an internal corset [30].

There were several studies that investigated the effects of stabilization exercise using a Swiss ball on the trunk muscle activity. Vera-Garcia et al. [30] examined the changes in trunk muscle activities according to the use of a Swiss ball during sit-up [31]. They found that using a Swiss ball led to higher trunk muscle activity. Other studies that compared muscle activity according to the use of a Swiss ball during trunk stabilization exercise also found that muscle activities were higher when using a Swiss ball. It is speculated that the left-right rocking of the Swiss ball would have contributed to increasing activities of muscles around the spine by stimulating the vestibular sense.

In the present study, there were significant differences in the IOM activities between Exercises 1 and 2 and Exercise 1 and 3 but not between Exercise 2 and 3. The postures in Exercises 2 and 3 led to higher trunk muscle activity than Exercise 1 because the former induced postural instability by only placing the below-elbow area and legs on the ball.

The high IOM and EOM activities during Exercise 3 were believed to be due to the following reasons: instability of the supporting surface might be a cause. In order to maintain balance on an unstable surface, co-contraction of muscles that cross the body segment happens [15]. The left-right instability of a Swiss ball may increase the burden of spinal rotation. The left-right rotation of the trunk is controlled by muscles that run transversely or horizontally, such as IOM, EOM, and transverse abdominal muscle, as opposed to the muscles that are aligned vertically, such as the rectus abdominis muscle [15,29]. Therefore, IOM and EOM co-contracts in order to overcome the left-right instability of the Swiss ball, which significantly increased muscle activity. Differences in the sensory inputs as a result of differences in the supporting surfaces may be another reason. Somatosensory input influences balance maintenance [15].

During maintenance of posture using a Swiss ball, somatosensory information is inputted only from the center of the trunk, and hence, activities of the oblique muscles were elevated to overcome difficulties in maintaining balance. Stimulation of the vestibular sense may be another cause because it is highly crucial for controlling balance. Thus, the level of trunk muscle activity differs according to the task and level of stability needed to maintain the posture.

A limitation of this study is that the sample was limited to men and women in their 20 s and did not consider the features of other age groups and sex. Among the muscles that contribute to spinal stability, the transverse abdominal muscle, IOM, and EOM are deep muscles, and because the surface EMG used in this study can only be used to collect EMG signals from the muscles in the surface layer, the low level of accuracy is another limitation of this study. Considering that it would be difficult to detect pure signals from IOM and EOM because IOM is anatomically located underneath the transverse abdominal muscle, we assumed the IOM and transverse abdominal muscle as one muscle for the measurements. Therefore, it would be difficult to generalize our findings to all populations. Subsequent studies should address the above limitations to examine muscle activity dur- 
ing stabilization exercises. Our results may be used as basic data for reducing low back pain and performing trunk stabilization exercises.

In conclusion, this study aimed to assess the activities of muscles that contribute to trunk stabilization during exercises using a Swiss ball, so as to provide data needed to design exercises for trunk stabilization in healthy adults. The following results were obtained.

First, there were significant differences in the IOM and EOM activities according to the type of trunk stabilization exercise $(p<0.05)$. Second, there were significant differences in the IOM activity between Exercises 1 and 2 and between Exercise 1 and $3(p<0.05)$. However, there were no significant differences in the IOM activity between Exercises 2 and 3 . Third, there were significant differences in the IOM activity between Exercises 1 and 2, Exercises 1 and 3, and Exercises 2 and $3(p<0.05)$.

Therefore, choosing the type and intensity of trunk stabilization exercises that are appropriate for each muscle to boost the effects of exercise is recommended.

\section{Conflict of Interest}

The authors declared no potential conflicts of interest with respect to the authorship and/or publication of this article.

\section{References}

1. Lee JY. Effects of aerobic exercise on body composition and blood lipid in middle-aged obesity woman [Master thesis]. Seoul: Korea University; 2002.

2. Kwon HR. The effects of lumbar self-exercise program on physical strength factors (strength, flexibility), pain and OSI in patients with the chronic low back pain [Master thesis]. Seoul; Ewha Womans University; 2005.

3. Akuthota V, Nadler SF. Core strengthening. Arch Phys Med Rehabil 2004;85(3 Suppl 1):S86-92.

4. Granata KP, Lee PE, Franklin TC. Co-contraction recruitment and spinal load during isometric trunk flexion and extension. Clin Biomech (Bristol, Avon) 2005;20:1029-37.

5. McGill SM, Grenier S, Kavcic N, Cholewicki J. Coordination of muscle activity to assure stability of the lumbar spine. J Electromyogr Kinesiol 2003;13:353-9.

6. Brill PW, Couzens GS. The core program: 15 minutes a day that can change your life. New York (NY): Bantam Books; 2001. p. $1-231$.

7. Panjabi M, Abumi K, Duranceau J, Oxland T. Spinal stability and intersegmental muscle forces. A biomechanical model. Spine (Phila Pa 1976) 1989;14:194-200.

8. Peate WF, Bates G, Lunda K, Francis S, Bellamy K. Core strength: a new model for injury prediction and prevention. J Occup Med Toxicol 2007;2:3.

9. Arokoski JP, Valta T, Airaksinen O, Kankaanpää M. Back and abdominal muscle function during stabilization exercises. Arch Phys Med Rehabil 2001;82:1089-98.

10. Kavcic N, Grenier S, McGill SM. Quantifying tissue loads and spine stability while performing commonly prescribed low back stabilization exercises. Spine (Phila Pa 1976) 2004;29:2319-29.

11. Marshall PW, Murphy BA. Core stability exercises on and off a Swiss ball. Arch Phys Med Rehabil 2005;86:242-9.

12. Panjabi MM. The stabilizing system of the spine. Part I. Function, dysfunction, adaptation, and enhancement. J Spinal Disord 1992;5:383-9; discussion 397.

13. Richardson CA, Jull GA. Muscle control-pain control. What exercises would you prescribe? Man Ther 1995;1:2-10.

14. Andersson EA, Nilsson J, Ma Z, Thorstensson A. Abdominal and hip flexor muscle activation during various training exercises. Eur J Appl Physiol Occup Physiol 1997;75:115-23.

15. Neumann DA. Kinesiology of the musculoskeletal system: foundations for physical rehabilitation. St. Louis: Mosby; 2002.

16. Richardson C, Hodges P, Hides J. Therapeutic exercise for lumbopelvic stabilization: a motor control approach for the treatment and prevention of low back pain. 2nd ed. Amsterdam: Churchill Livingston; 2004.

17. Reeves NP, Cholewicki J. Modeling the human lumbar spine for assessing spinal loads, stability, and risk of injury. Crit Rev Biomed Eng 2003;31:73-139.

18. Kim KY, Shin SB, Kang JH, Lee KI, Kim YS. Physical science: the effects of exercise for trunk muscle using Swiss ball in chronic low back patients. J Korea Sport Res 2006;17:101-12.

19. Yuk DH. Effect of Swiss ball lumbar stabilization exercise on the balance, oswestry disability index of chronic low back pain patients [Master thesis]. Seoul: Sahmyook University; 2010.

20. Karatas M, Cetin N, Bayramoglu M, Dilek A. Trunk muscle strength in relation to balance and functional disability in unihemispheric stroke patients. Am J Phys Med Rehabil 2004;83:81-7.

21. Kim LC. The effects of core stability exercise with physioball and floor exercise on electromyographic activity of selected trunk and abdominal muscles and balance in healthy adults [Master thesis]. Cheonan: Dankook University; 2004.

22. Hall CM, Brody LT. Therapeutic exercise: moving toward function. Philadelphia: Lippincott Williams \& Wilkins; 1999.

23. Magerl F, Aebi M, Gertzbein SD, Harms J, Nazarian S. A comprehensive classification of thoracic and lumbar injuries. Eur Spine J 1994;3:184-201.

24. Roaf R. A study of the mechanics of spinal injuries. J Bone Joint Surg 1960;42:810-23.

25. Han SW, Cho SY, Kim YS, Lee HJ, Oh TY, Kong SA. The effect of isometric exercise using Swiss ball on the flexibility, the strength and the waist and hip circumferences. J Korean Soc Phys Ther 2001;13:73-82.

26. Lehman GJ, Hoda W, Oliver S. Trunk muscle activity during bridging exercises on and off a Swiss ball. Chiropr Osteopat 2005;13:14.

27. Escamilla RF, Lewis C, Bell D, Bramblet G, Daffron J, Lambert $\mathrm{S}$, et al. Core muscle activation during Swiss ball and traditional abdominal exercises. J Orthop Sports Phys Ther 2010;40:26576. 
28. Stevens VK, Coorevits PL, Bouche KG, Mahieu NN, Vanderstraeten GG, Danneels LA. The influence of specific training on trunk muscle recruitment patterns in healthy subjects during stabilization exercises. Man Ther 2007;12:271-9.

29. Stuge B, Veierød MB, Laerum E, Vøllestad N. The efficacy of a treatment program focusing on specific stabilizing exercises for pelvic girdle pain after pregnancy: a two-year follow-up of a randomized clinical trial. Spine (Phila Pa 1976) 2004;29:E197E203.
30. Vera-Garcia FJ, Grenier SG, McGill SM. Abdominal muscle response during curl-ups on both stable and labile surfaces. Phys Ther 2000;80:564-9.

31. Shumway-Cook A, Woollacott MH. Motor control: theory and practical applications. Baltimore: Lippincott Williams \& Wilkins; 1995.

32. Lee HS, Choi HS, Kwon OY. A literature review on balance control factors. Phys Ther Korea 1996;3:82-91. 